\title{
Method for Uncertainty Evaluation of Vicarious Calibration of Spaceborne Visible to Near Infrared Radiometers
}

\author{
Kohei Arai ${ }^{1}$, Wahyudi Hasbi ${ }^{2}$, A Hadi Syafrudin ${ }^{3}$, Patria Rachman Hakim ${ }^{4}$, Sartika Salaswati ${ }^{5}$, Lilik Budi Prasetyo ${ }^{6}$, \\ Yudi Setiawan ${ }^{7}$ \\ Graduate School of Science and Engineering, Saga University, Japan ${ }^{1}$ \\ LAPAN: Satellite Technology Center, Indonesian National Institute of Aeronautics and Space, Bogor Indonesia ${ }^{2,3,4,5}$ \\ Forest Faculty, IPB: Bogor Agricultural University, Bogor Indonesia, ${ }^{6,7}$
}

\begin{abstract}
A method for uncertainty evaluation of vicarious calibration for solar reflection channels (visible to near infrared) of spaceborne radiometers is proposed. Reflectance based at sensor radiance estimation method for solar reflection channels of radiometers onboard remote sensing satellites is also proposed. One of examples for vicarious calibration of LISA: Line Imager Space Application onboard LISAT: LAPAN-IPB Satellite is described. Through the preliminary analysis, it is found that the proposed uncertainty evaluation method is appropriate. Also, it is found that percent difference between DN: Digital Number derived radiance and estimated TOA: Top of the Atmosphere radiance (at sensor radiance) ranges from 3.5 to $9.6 \%$. It is also found that the percent difference at shorter wavelength (Blue) is greater than that of longer wavelength (Near Infrared: NIR). In comparison to those facts to those of Terra/ASTER/VNIR, it is natural and reasonable.
\end{abstract}

Keywords-Field experiment; vicarious calibration; image quality evaluation

\section{INTRODUCTION}

In order to calibrate optical mission instruments onboard remote sensing satellites in flight, vicarious calibration is strongly needed. One of the problems of vicarious calibration of optical instruments onboard remote sensing satellites is poor accuracy in comparison to the ground based calibration accuracy because estimation of atmospheric influences is not so easy.

Error budget analysis of vicarious calibration including uncertainty evaluation is reported. It, however, is still difficult to justify the uncertainty evaluation. Error budget analysis of reflectance based vicarious calibration method for satellite based visible to near infrared radiometers is discussed [1]. On the other hand, atmospheric correction and vicarious calibration of $\mathrm{ADEOS}^{1}$ (Advanced Earth Observing Satellite) /AVNIR (Advanced Visible and Near Infrared Radiometer) and OCTS (Ocean Color and Temperature Scanner) is investigated [2]. Meanwhile, reflectance based vicarious calibration accuracy improvement by means of onsite measuring instruments calibration for satellite based visible to near infrared radiometers is proposed [3].

1 http://www.jaxa.jp/projects/sat/adeos/index_j.html
In this paper, one of the approaches for uncertainty evaluation is attempted. Major error would occur on surface reflectance measurements. Therefore, it is reasonable that uncertainty can be evaluated through surface measurement accuracy assessments. The proposed method is validated with Indonesian remote sensing mission instruments data of LISA: Line Imager Space Application is one main payload of the LISAT, LAPAN ${ }^{2}$ (Indonesian National Institute of Aeronautics and Space) - $\mathrm{IPB}^{3}$ (Bogor Agricultural University) Satellite $^{4}$. This imager consists of four channels, blue, green, red, and NIR: Near Infrared. LISA is standard camera which can produce image with Digital Number (DN) representation. Radiometric model is formulated for prediction of radiance input value from the DN. With a limited mechanical and electronic of lens and CCD: Charge Coupled Device, focus can be adjusted through trials of image acquisition.

The accuracy of the pre-launch calibration is estimated to approximately 8 percent [4]. The items of radiometric characterization of the sensor are (1) linearity, (2) DSNU (Dark Signal Uniformity) and (3) PRNU (Photo Response Non-Uniformity) [5]. LISA has own mechanical, electronic models. Therefore, it is possible to remove radiometric and geometric errors from the acquired imagery data with telemetry data [6].

The related research works and research background are described in the following section. Then, the proposed uncertainty evaluation method is described followed by some experiments for validation of the proposed method. Finally, conclusion is described with some discussions,

\section{RELATED RESEARCH WORKS OF VICARIOUS CALIBRATION}

Previously, results of the EOS $^{5}$ (Earth Observation Satellite System) vicarious calibration joint campaign at Lunar Lake Playa, Nevada (USA) which was conducted in 1996 is reported [7] while preliminary vicarious calibration for EOS-

\footnotetext{
${ }^{2}$ https://en.wikipedia.org/wiki/National_Institute_of_Aeronautics_and_Sp ace

${ }^{3}$ https://www.ipb.ac.id/

${ }^{4}$ https://directory.eoportal.org/web/eoportal/satellite-missions/content//article/lapan-a3

${ }^{5}$ https://eospso.gsfc.nasa.gov/
} 
AM1 (The first afternoon orbit satellite of EOS) /ASTER (Advanced Spaceborne Thermal Emission and Reflection Radiometer) with field campaign is also well reported [8]. Atmospheric correction and vicarious calibration of ADEOS/AVNIR and OCTS is proposed and validated [9] together with atmospheric correction and residual error in vicarious calibration of AVNIR and OCTS both onboard ADEOS [10]. Meanwhile, experimental study on vicarious calibration for ADEOS/AVNIR and OCTS (in particular for visible channels) is reported [11] and field experiments at Tsukuba test site which is situated in Japan for ASTER vicarious calibration (visible to shortwave infrared regions) is also reported [12] together with field experiments at Tsukuba test site for ASTER vicarious calibration (thermal infrared regions) [13].

Early results from vicarious calibration of ASTER/VNIR and SWIR at test site in Japan is well reported together with early results from vicarious calibration of ASTER/TIR at the test site in Japan [14]. Meantime, reflectance based vicarious calibration for solar reflection channels of radiometers onboard satellites with deserted area of data is proposed [15] together with vicarious calibration of ASTER/VNIR based on the results of aerosol optical property by sky-radiometer (aureole-meter ${ }^{6}$ ) at the test site in Saga, Japan [16].

Vicarious calibration of ASTER based on the reflectance based approach is reported [17]. Meanwhile, error analysis and sensitivity analysis in estimation of aerosol refractive index and size distribution using polarization radiance measurement data for vicarious calibration of remote sensing satellite carrying visible to shortwave infrared radiometer is conducted and reported [18].

Influence due to aerosol size distribution on vicarious calibration accuracy and influence of calibration accuracy of the used sky radiometer in estimation of aerosol refractive index and size distribution is investigated [19]. On the other hand, vicarious calibration based cross calibration (through a comparison between the different sensor images, calibration is conducted mutually) of solar reflective channels of radiometers onboard remote sensing satellite and evaluation of cross calibration accuracy through band-to-band data comparisons is proposed and reported [20]. Then, a comparison among cross, onboard, and vicarious calibration for Terra ${ }^{7} /$ ASTER/VNIR is made [21].

Sensitivity analysis and error analysis of reflectance based vicarious calibration with estimated aerosol refractive index and size distribution derived from measured solar direct and diffuse irradiance as well as measured surface reflectance is conducted [22]. Also, vicarious calibration data screening method based on variance of surface reflectance and atmospheric optical depth together with cross calibration is proposed and discussed [23]. Furthermore, vicarious calibration data screening method based on variance of surface reflectance and atmospheric optical depth together with cross calibration is proposed and discussed [24].

\footnotetext{
${ }^{6}$ https://sites.google.com/site/aerosolpedia/yong-yurisuto/da-qiearozoruguan-ce/9

${ }^{7}$ https://terra.nasa.gov/about/terra-instruments/aster
}

In this paper, the proposed method for vicarious calibration of solar reflection channels of mission instruments onboard satellites which includes estimation of at sensor radiance) is described in particular for "uncertainty evaluation" followed by the first attempt of the proposed uncertainty evaluation through vicarious calibration of LISA.

\section{Proposed Uncertainty Evaluation Method For Vicarious Calibration of Optical Sensors}

The vicarious calibration method is illustrated in Fig. 1.

Surface reflectance can be measured through a comparison between radiance from standard plaque (Spectralon ${ }^{8}$ which is traceable to NIST ${ }^{9}$ (National Institute of Standards and Technology) standard) and the surface in concern. There is Bidirectional Reflectance Distribution Function: BRDF $^{10}$ of standard plaque and the surface. Major error sources are (1) BRDF effects, (2) Instability of the hand held spectrometer for surface reflectance measurement, (3) Registration error between the pixels of the test site and measured surface, (4) Instability of sensitivity of the spectrometer, etc. On the other hand, solar irradiance is quite stable (solar constant). Therefore, incoming radiance is assumed to be stable when the sky is clear. Total optical depth ${ }^{11}$ can be measured with fine accuracy together with column water vapor, ozone. Meanwhile, Rayleigh scattering component ${ }^{12}$ can be calculated with atmospheric pressure and air temperature (compensation). From the total optical depth, it is possible to calculate aerosol optical depth with the calculated optical depth of Rayleigh component, optical depth of water vapor, ozone. Using MODTRAN ${ }^{13}$ of atmospheric model (Software code), influence due to the atmosphere can be calculated precisely.

Proposed uncertainty evaluation method is based on surface reflectance measurement data. It is reasonable that uncertainty is supposed to be caused by a homogeneity of the surface. Therefore, standard deviation of surface reflectance over double size areas of Instantaneous Field Of View: IFOV at the surface of the test site is considered to be uncertainty.

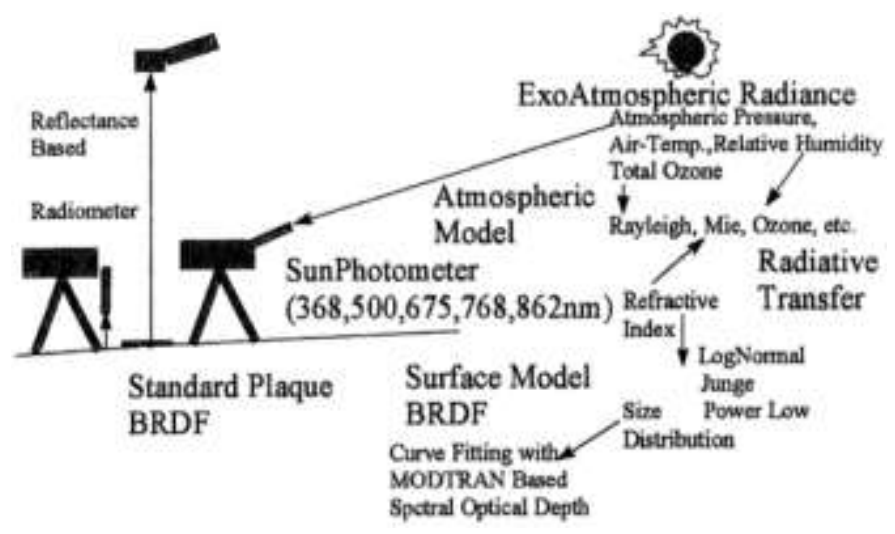

Fig. 1. Illustrative View of Vicarious Calibration.

\footnotetext{
${ }^{8}$ https://en.wikipedia.org/wiki/Spectralon

${ }^{9}$ https://www.nist.gov/

${ }^{10} \mathrm{https} / / /$ ja.wikipedia.org/wiki/BRDF

${ }^{11} \mathrm{https} / / /$ en.wikipedia.org/wiki/Optical_depth

${ }^{12} \mathrm{https} / / /$ en.wikipedia.org/wiki/Rayleigh_scattering

${ }^{13} \mathrm{http}: / /$ modtran.spectral.com/
} 


\section{Validation of the Proposed Method Through VICARIOUS CALIBRATION OF LISA}

\section{A. Method for Reflectance based Vicarious Calibration}

The proposed vicarious calibration of solar reflection channels of mission instruments onboard satellites is based on reflectance based method. The major influencing factor on the estimation of at sensor radiance (TOA: Top of the Atmosphere radiance) is surface reflectance measurements followed by absorption and scattering in the atmosphere. In order to improve surface reflectance measuring accuracy, wide areas of surface reflectance has to be measured. Then, mean and variance are checked for increasing reliability of the measurement data. Atmospheric absorption and scattering components are taken into account in the MODTRAN together with solar irradiance at the top of the atmosphere (extraterrestrial solar irradiance, solar constant that is Kurucz Model $^{14}$ ).

From field experiments, surface reflectance is measured together with atmospheric conditions such as atmospheric optical depth, atmospheric pressure (atmospheric optical depth due to atmospheric molecule can be estimated with atmospheric pressure and air temperature), air temperature, relative humidity, water vapor in the atmosphere, to column ozone. From these measured data, the TOA radiance (it is totally equal to at sensor radiance is estimated by using atmospheric code of MODTRAN ${ }^{15}$. Then, the estimated TOA radiance is compared to the observed sensor radiance. The difference between both the radiances is calibration coefficient.

In order to minimize measuring error for surface reflectance, 10 by 10 pixels of homogenous area of test site is used together with standard plaque of Spectralon which is traceable to NIST standard. This is the key issue here for the proposed method together with the optical depth measuring instruments of MicroTops-II ${ }^{16}$ of ozone meter and atmospheric transparency measurements.

\section{B. Major Specification of LISA}

LAPAN-A3/LAPAN-IPB (LISAT) was launched by PSLV: Polar Satellite Launch Vehicle Rocket ${ }^{17}$, together with other 19 satellites from many countries from Sriharikota, India on Wednesday 22 June 2016. Major orbital parameters are as follows:

Altitude: $505 \mathrm{~km}$ (polar orbit)

Inclination: 98 degree

Major specification of LISAT satellite is as follows,

Weight: $115 \mathrm{~kg}$

Dimension: 500 x 574 x $424 \mathrm{~mm}$

LISAT carries the following equipment's,

a. AIS (Automatic Identification System) ${ }^{18}$

b. LISA: Push-broom 4 bands multispectral imager (300 $\mathrm{mm}$ ). (Swath width: $122.4 \mathrm{~km}$, Resolution: $18 \mathrm{~m}$ ) 657

${ }^{14} \mathrm{https} / / /$ aslopubs.onlinelibrary.wiley.com/doi/pdf/10.4319/lo.1990.35.8.1

${ }^{15} \mathrm{http}: / /$ modtran.spectral.com/

${ }^{16} \mathrm{https} / / /$ solarlight.com/product/microtops-ii-sunphotometer/

${ }^{17}$ https://en.wikipedia.org/wiki/Polar_Satellite_Launch_Vehicle

${ }^{18}$ https://www.marinetraffic.com/

\section{c. DSC: Digital Space Camera $(1000 \mathrm{~mm})$}

Outlook of LISAT is shown in Fig. 2. LISAT satellite is operated at the operational station situated at LAPAN, Norwegian, Berlin \& Bogor, Indonesia. Revisit cycle of LISAT is 21 days. Major spectral specification of LISA is shown in Table 1.

LISA has four bands whose wavelength ranges from 410 to $900 \mathrm{~nm}$, blue, green, red, and Near Infrared: NIR. IFOV of LISA is $18 \mathrm{~m}$. Furthermore, swath width of LISA is $122.4 \mathrm{~km}$. Also, LISA imagery data is acquired with 16 bit of quantization levels. Spectral response of each band is shown in Fig. 3.

TABLE I. FWHM AND AVERAGE RADIANCE VOLTAGE TO RADIANCE CONSTANTA

\begin{tabular}{|l|l|l|l|}
\hline Band & FWHM & Bandwidth & Radiance $(\mathrm{mW} / \mathrm{cm} 2$-sr-um $)$ \\
\hline Blue & $0.410-0.490$ & 0.080 & 41.76 \\
\hline Green & $0.510-0.580$ & 0.070 & 29.69 \\
\hline Red & $0.630-0.700$ & 0.070 & 20.45 \\
\hline NIR & $0.770-0.900$ & 0.130 & 23.43 \\
\hline
\end{tabular}

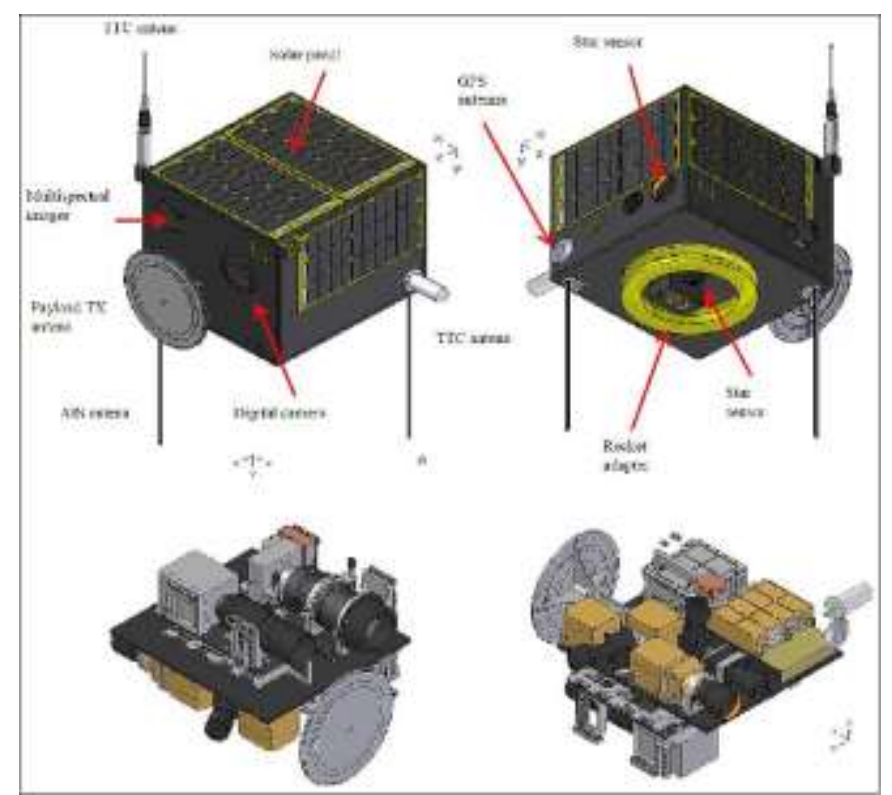

Fig. 2. Outlook of LISAT Satellite.

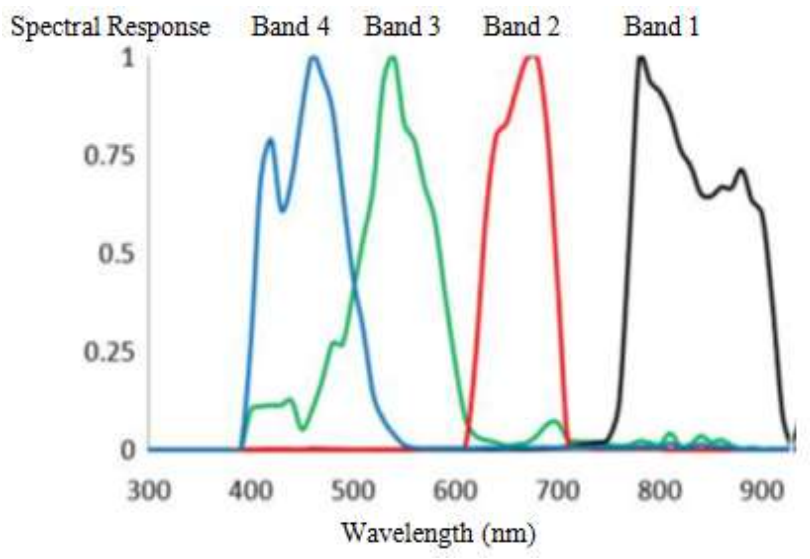

Fig. 3. Spectral Response of LISA. 


\section{Field Campaign}

Field experiments are conducted at the test site of Kupang on 11 and 12 April 2018. The location of Kupang test site is shown in Fig. 4. As shown in Fig. 4, it was partially cloudy condition for both 11 and 12 April. At the test site, blue tarp ( $15 \mathrm{~m}$ by $15 \mathrm{~m})$ is set-up.

The conditions of the field campaign are as follows:

Location: 10:12'07.8"S, 123:33'05.2"

Air-temperature: 34.3 deg.(Apr.11), 32.2 Deg.(Apr.12)

Relative Humidity: 50.6\% (Apr.11), 58.6\%(Apr.12)

Atmospheric pressure: $1006 \mathrm{hPa}$

Column ozone: 290 DU

(ftp://toms.gsfc.nasa.gov/pub/omi/data/ozone/Y2018/L3_o zone_omi_20180412.txt)

Junge parameter: 6.49

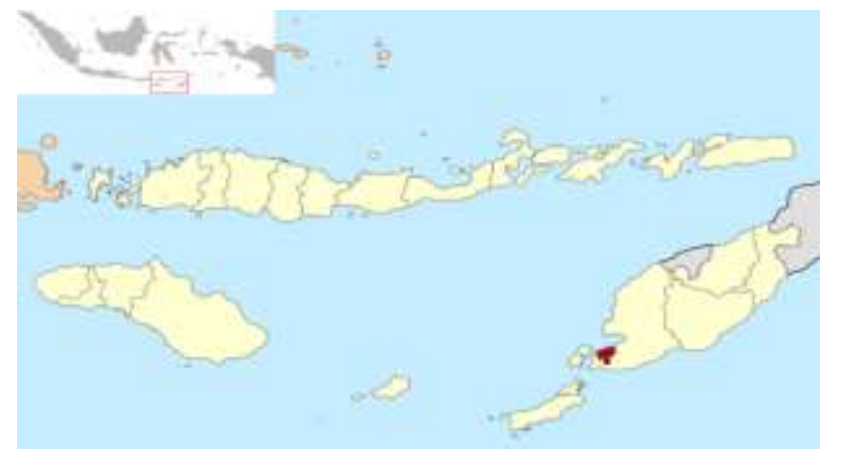

Fig. 4. Location of Kupang Test Site.

As shown in Fig. $5,15 \mathrm{~m}$ by $15 \mathrm{~m}$ of blue tarp is set-up at the test site for identification of the test site location in the acquired LISA image. In the test site, surface reflectance at 30 $\mathrm{m}$ by $30 \mathrm{~m}$ of test site area is measured by $5 \mathrm{~m}$ intervals.

\section{Measured Data}

The surface reflectance is measured with the well-known FieldSpec Hand Held $2^{19}$. Specification manufactured by ASD Incorporation. The FieldSpec Hand Held 2 delivers precision full range spectral measurements through a hand-held system designed around a radically streamlined cable-free workflow. Outlook of FieldSpec Hand Held 2 Specification manufactured by ASD Incorporation is shown in Fig. 6.

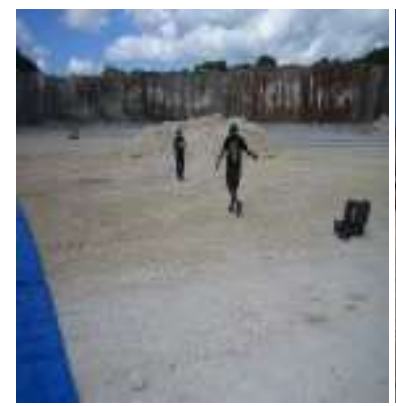

(a) April 112018

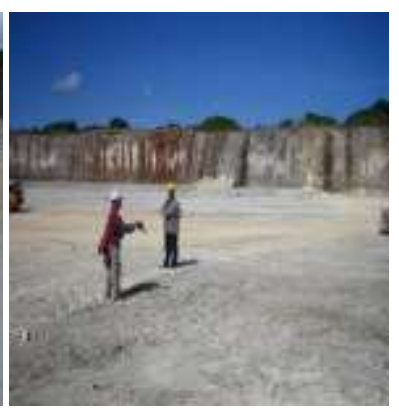

(b) April 122018
Fig. 5. Photos of the Field Experiments.

\footnotetext{
${ }^{19} \mathrm{https}: / / \mathrm{www}$. malvernpanalytical.com/en/products/product-range/asdrange/fieldspec-range/index.html
}

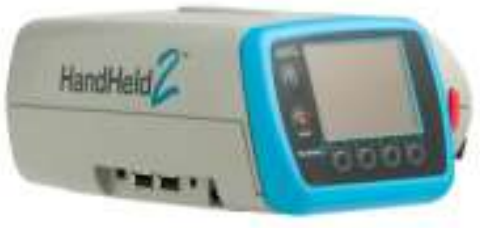

Fig. 6. Outlook of the FieldSpec Hand Held 2 Portable Spectrometers Used.

Also, major specification of the FieldSpec Hand Held 2 Specification manufactured by ASD Incorporation is shown in Table 2.

An example of the measured surface reflectance of the test site of Kupang is shown in Fig. 7. As a working standard plaque, back side of photoprint paper which is traceable to Spectralon manufactured by Labsphere Co. Ltd. is used.

LISA image of Kupang of the test site which is acquired on April 122018 is shown in Fig. 8(a) while the enlarged Kupang test site LISA image is shown in Fig. 8(b).

TABLE II. MAJOR SPECIFICATION OF THE FIELDSPEC HAND HELD 2 FIELDSPEC HAND HELD 2

\begin{tabular}{|l|l|}
\hline Wavelength Range & $325-1075 \mathrm{~nm}$ \\
\hline $\begin{array}{l}\text { Wavelength } \\
\text { Accuracy }\end{array}$ & $\pm 1 \mathrm{~nm}$ \\
\hline Spectral Resolution & $<3 \mathrm{~nm}$ at $700 \mathrm{~nm}$. \\
\hline Integration Time & $8.5 \mathrm{~ms}$ minimum (selectable) \\
\hline Field-of-View & $25^{\circ}($ Optional fore optics available) \\
\hline Sampling Interval & $1.5 \mathrm{~nm}$ for the spectral region $325-1075 \mathrm{~nm}$. \\
\hline Spectrum File size & Approximately $30 \mathrm{~KB}$ \\
\hline Memory Storage & Up to 2,000 spectrum files \\
\hline Weight & $1.2 \mathrm{~kg}(2.6$ lbs.) with batteries \\
\hline Body Dimensions & $\begin{array}{l}\text { Measurements with handle not attached (width } \mathrm{x} \\
\text { depth } \mathrm{x} \text { height): } \\
90 \text { x } 140 \mathrm{x} 215 \text { mm }(3.5 \mathrm{x} 5.5 \mathrm{x} 8.5 \text { in) }\end{array}$ \\
\hline Temperature Range & $\begin{array}{l}\text { Operating Temperature: } 0^{\circ} \text { to } 40^{\circ} \mathrm{C}\left(32^{\circ} \text { to } 104^{\circ} \mathrm{F}\right) \\
\text { Storage Temperature: } 0^{\circ} \mathrm{C} \text { to } 45^{\circ} \mathrm{C}\left(32^{\circ} \text { to } 113^{\circ} \mathrm{F}\right) \\
\text { Operating and Storage Humidity: } 90 \% \text { Non- } \\
\text { condensing }\end{array}$ \\
\hline
\end{tabular}

Reflectance 12042018-Prof Base

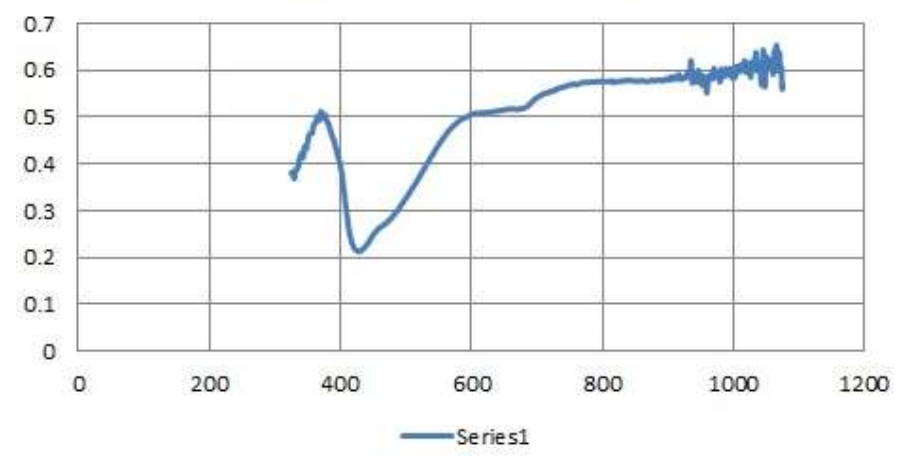

Fig. 7. Surface Reflectance of the Test Site Kupang on April 122018. 


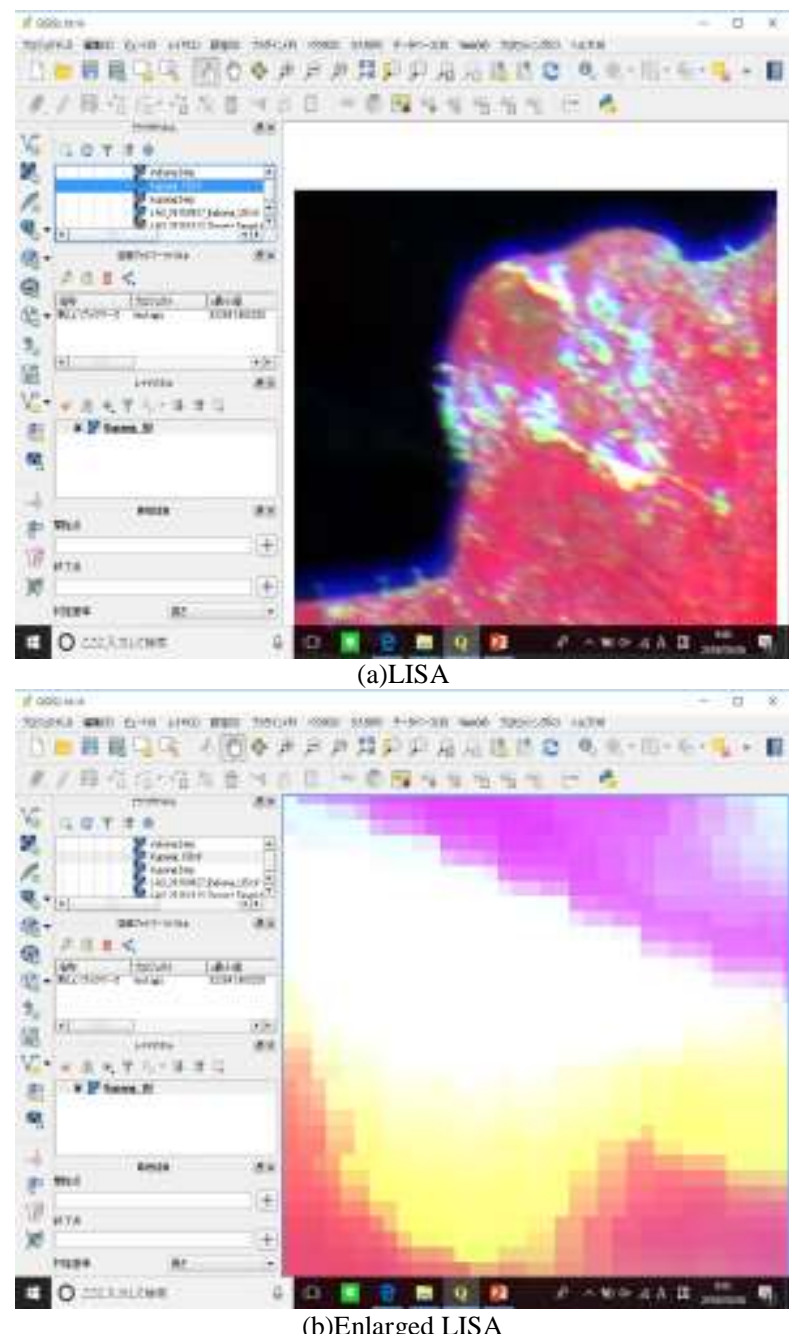

Fig. 8. LISA Image of Kupang Test Site Acquired on April 122018.

The locations of the 10 pixels of the surrounding pixels of the test site of Kupang in the LISA image are shown in Fig. 9.
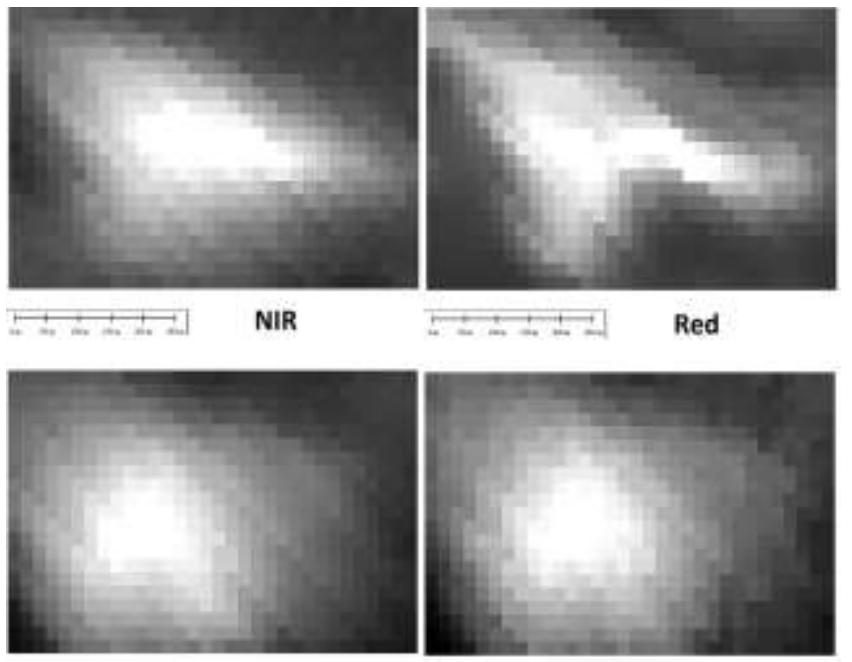

Green
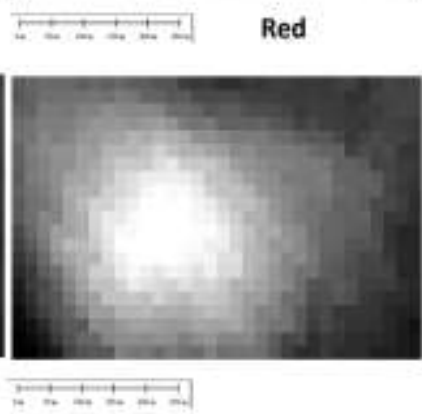

Fig. 9. LISA Image of the Test Site, Kupang.
TABLE III. DN OF THE PIXELS OF THE SURROUNDING THE TEST SITE OF KUPANG

\begin{tabular}{|l|l|l|l|l|}
\hline Band & 4 & 3 & 2 & 1 \\
\hline Point & Blue & Green & Red & NIR \\
\hline 1 & 4138 & 13318 & 22469 & 14012 \\
\hline 2 & 4686 & 15248 & 28234 & 14031 \\
\hline 3 & 4621 & 15007 & 28213 & 14383 \\
\hline 4 & 4726 & 15595 & 27004 & 13627 \\
\hline 5 & 4599 & 14680 & 23497 & 14462 \\
\hline 6 & 4698 & 15611 & 28339 & 14212 \\
\hline 7 & 4592 & 15098 & 25828 & 14575 \\
\hline 8 & 4680 & 15525 & 28549 & 14014 \\
\hline 9 & 4621 & 15007 & 28213 & 14383 \\
\hline 10 & 4656 & 15646 & 26624 & 13220 \\
\hline Average & 4601.7 & 15073.5 & 26697 & 14091.9 \\
\hline Standard Deviation & 168.9096 & 696.738 & 2161.678 & 414.5633 \\
\hline
\end{tabular}

From the LISA imagery data, Digital Number: DN of the pixels of the surrounding the test site point of Kupang is shown in Table 3.

\section{E. Uncertainty}

Uncertainty of the vicarious calibration of this case is evaluated with the measured data in the Kupang test site described in the previous sub-section. Taking the ratio of standard deviation and the average in the Table 3, the uncertainty, $\mathrm{U}$ can be evaluated. The result is shown in Table 4 . In the table, averaged uncertainty over the all bands is also shown. It is found that the averaged uncertainty of the vicarious calibration in Kunag test site is 0.048 .

TABLE IV. UNCERTAINTY OF VICARIOUS CALIBRATION IN KUNAG TEST SITE

\begin{tabular}{|l|l|l|l|l|l|}
\hline Band No. & 4 & 3 & 2 & 1 & Average \\
\hline $\mathrm{U}$ & 0.036706 & 0.046223 & 0.080971 & 0.029419 & 0.048329 \\
\hline
\end{tabular}

\section{F. Atmospheric Data}

Microtops II of measuring instrument manufactured by Solar Light Co. Ltd. is used for Langley plot and optical depth. Solar Light's Model 540 Microtops II Sunphotometer is a light weight, portable 5 channel instrument for measuring aerosol optical thickness, direct solar irradiance, and water vapor column easily, accurately and dependably. Fig. 10 shows outlook of the MIcrotops II. Microtops II measures solar direct irradiance at the following five wavelength, 340, $500,675,870,1020 \mathrm{~nm}$.

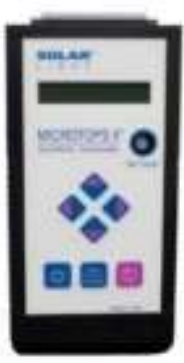

Fig. 10. Outlook of Microtops II. 


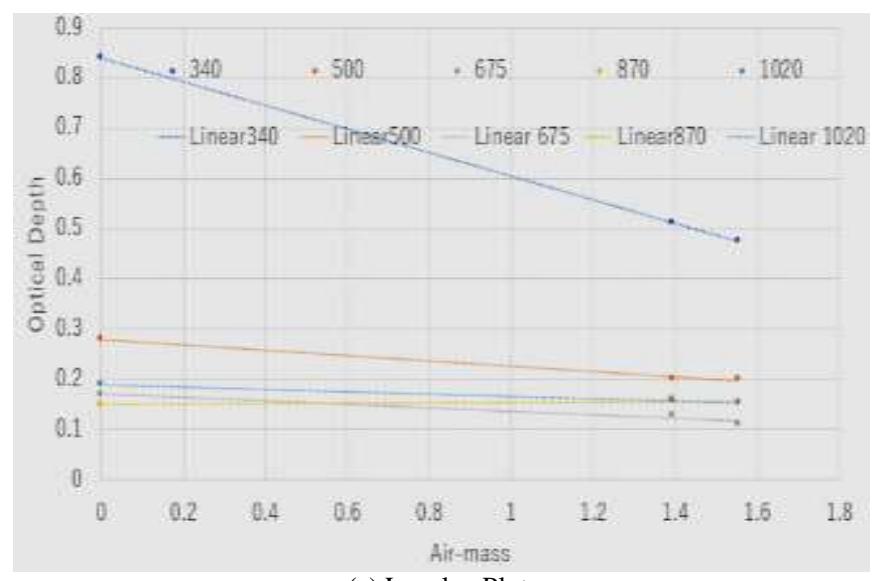

(a) Langley Plot.

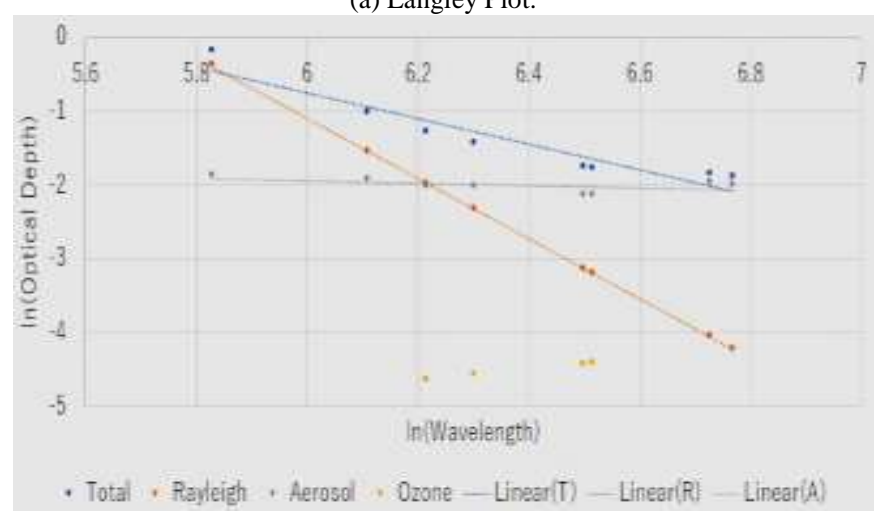

(b)Total Optical Depth.

Fig. 11. Measured Langley Plot and Total Atmospheric Optical Depth.

Meanwhile, measured Langley plot $^{20}$ and total atmospheric optical depth on April 122018 is shown in Fig. 11(a) and (b), respectively.

From the measured total optical depth, optical depth of Rayleigh scattering (atmospheric molecule), ozone, water vapor, and aerosol (Mie scattering ${ }^{21}$ ) are calculated. There are absorption due to water vapor, ozone and scattering of Rayleigh (atmospheric molecule) and Mie (aerosol). As shown before, total column ozone is retrieved from the aforementioned Web site. On the other hand, water vapor profile can be retrieved from the MODTRAN with the Typical tropic atmospheric model (relative humidity on the ground is adjusted with the measured humidity on April 12 2018).

Meanwhile, Rayleigh scattering component is derived from the measured atmospheric pressure. Optical depth of aerosol can be calculated with equation (1).

\section{ODaero=ODtotal-ODrayleigh-ODwater-ODozone}

\section{G. Vicarious Calibration Coefficients}

Continuous atmospheric optical depth of total, Rayleigh, water vapor, ozone and aerosol are then calculated with MODTRAN through curve fitting between observed and calculated optical depth with MODTRAN in a least square mean. Also, TOA radiance (at sensor radiance) is calculated based on MODTRAN with input parameters of the measured

\footnotetext{
${ }^{20}$ https://en.wikipedia.org/wiki/Langley_extrapolation

${ }^{21} \mathrm{https} / / / \mathrm{en}$.wikipedia.org/wiki/Mie_scattering
}

surface reflectance, geometric relation among the satellite position, test site location, and sun elevation and azimuth angle (direction of direct solar irradiance) as well as atmospheric parameters including optical depth. Therefore, TOA radiance can be calculated with the integration of TOA radiance multiplied by the LISA spectral response. Then, at sensor radiance is compared to the LISA imagery data derived radiance. Thus, vicarious calibration coefficient can be calculated.

Surface reflectance, atmospheric optical depth, and the other required parameters are input to MODTRAN for calculation of Top of the Atmosphere: TOA radiance for each band of LISA. The calculated DN derived radiance and the TOA radiance are shown in Table 5 together with percent difference between both. As the results of the vicarious calibration, it is found that vicarious calibration coefficients are calculated as shown in Table 5. Table 5 shows the percent difference between DN derived radiance and estimated TOA radiance (at sensor radiance) ranges from 3.5 to $9.6 \%$.

TABLE V. CALCULATED DN DERIVED RADIANCE AND THE TOA RADIANCE

\begin{tabular}{|l|l|l|l|l|l|}
\hline \multicolumn{7}{|l|}{ Average of near Blue Trap Position } \\
\hline Band & 4 & 3 & 2 & 1 & \\
\hline Name & B & G & R & N & \\
\hline Reflectance & 0.312 & 0.535 & 0.648 & 0.767 & Unitless \\
\hline DN Radiance & 0.525 & 0.925 & 0.899 & 0.409 & $\mathrm{~W} / \mathrm{m}^{2} / \mathrm{sr} / \mathrm{nm}$ \\
\hline DN Radiance & 52.472 & 92.452 & 89.885 & 40.909 & $\mathrm{~mW} / \mathrm{cm}^{2} / \mathrm{sr} / \mathrm{um}$ \\
\hline ToA Rad. & 50.64 & 87.55 & 83.5 & 37 & $\mathrm{~mW} / \mathrm{cm}^{2} / \mathrm{sr} / \mathrm{um}$ \\
\hline$\%$ Diff. & 3.49 & 5.3 & 7.1 & 9.56 & $\%$ \\
\hline
\end{tabular}

\section{CONCLUSION}

The proposed uncertainty evaluation method for vicarious calibration is validated with the LISAT/LISA vicarious calibration in Kupang test site. The uncertainty is $0.048 \%$ which is reasonable from the point of view of the empirical field experiments.

Reflectance based at sensor radiance estimation method for solar reflection channels of radiometers onboard remote sensing satellites is proposed. Also, one of examples for vicarious calibration of LISA: Line Imager Space Application onboard LISAT: LAPAN-IPB Satellite is described.

Through the preliminary analysis, it is found that the percent difference between DN: Digital Number derived radiance and estimated TOA: Top of the Atmosphere radiance (at sensor radiance) ranges from 3.5 to $9.6 \%$. It is also found that the percent difference at shorter wavelength (Blue) is greater than that of longer wavelength (Near Infrared: NIR). In comparison to those facts to those of Terra/ASTER/VNIR, it is natural and reasonable.

Further investigations are required for vicarious calibration and image quality evaluations together with validation of the proposed method for uncertainty evaluation. Also, cross 
calibration between LISAT/LISA and the other same spectral range of remote sensing imagers onboard satellites.

\section{ACKNOWLEDGMENTS}

Author would like to thank the participants of the field campaign conducted for vicarious calibration.

\section{REFERENCES}

[1] Kohei Arai, K.J.Thome, Error Budget Analysis of Reflectance Based Vicarious Calibration Method for Satellite Based Visible to Near Infrared Radiometers, Journal of Japan Society of Photogrammetry and Remote Sensing, Vol.39, No.2, pp.99-105,(2000).

[2] Kohei Arai, Atmospheric correction and vicarious calibration of ADEOS/AVNIR and OCTS, Advances in Space Research, Vol.25, No.5, pp.1051-1054, (2000).

[3] Kohei Arai, Reflectance Based Vicarious Calibration Accuracy Improvement by Means of Onsite Measuring Instruments Calibration for Satellite Based Visible to Near Infrared Radiometers, Journal of Japan Society of Photogrammetry and Remote Sensing, Vol.40, No.3, pp.2533, (2001).

[4] Leroy M, Henry P, Guenther B and McLean J 1990 Comparison of CNES spherical and NASA hemisphere large aperture integration sources Remote Sens. Environ. 31 97-104, 1990.

[5] Misgaiski-Hass M. and Hieronymus J 2014 Radiometric Calibration of dual Sensor Camera System, a Comparison of classical and low cost Calibration Int. Arch. Photogramm. Remote Sens. Spatial Inf. Sci. XL-5 421-424, https://doi.org/10.5194/isprsarchives-XL-5-421-2014.

[6] Mansouri A, Marzani F and Gouton P 2005 Development of a protocol for CCD calibration: application to a multispectral imaging system International Journal of Robotics and Automation 20(2) 94-100, 2005.

[7] K. Thome, S. Schiller, J. Conel, Kohei Arai and S. Tsuchida, Results of the 1996 EOS vicarious calibration joint campaign at Lunar Lake Playa, Nevada(USA), Metrologia, Vol.35, pp.631-638, Jan.1999.

[8] Kohei Arai, Preliminary vicarious calibration for EOS-AM1/ASTER with field campaign, Advances in Space Research, Vol.23, No.8, pp.1449-1457, June 1999.

[9] Kohei Arai, Atmospheric correction and vicarious calibration of ADEOS/AVNIR and OCTS, Advances in Space Research, Vol.25, No.5, pp.1051-1054, 2000.

[10] Kohei Arai, Atmospheric correction and residual error in vicarious calibration of AVNIR and OCTS both onboard ADEOS, Advances in Space Research, Vol.25, No.5, pp.1055-1058, 2000.

[11] Kohei Arai, Yasunori Terayama, Experimental Study on Vicarious Calibration for ADEOS/AVNIR and OCTS(Visible Channels), Journal of Japan Society of Photogrammetry and Remote Sensing, Vol.38, No.6, pp.34-40, 2000.

[12] Kohei Arai, K.J.Thome, Satoshi Tsuchida, Tsutomu Takashima, Tsuyoshi Kawata, Shoichi Machida, Hideyuki Tonooka, Field Experiments at Tsukuba Test Site for ASTER Vicarious Calibration (Visible to Shortwave Infrared Regions), Journal of Remote Sensing Society of Japan, Vol.20, No.1, pp.55-62, (2000).

[13] Hideyuki Tonooka, F.Palluconi, Kohei Arai, Tsuneo Matsunaga, Shuichi Rokukawa, Masatane Katoh, Field Experiments at Tsukuba Test Site for ASTER Vicarious Calibration (Thermal Infrared Regions), Journal of Remote Sensing Society of Japan, Vol.20, No.1, pp.63-70, (2000).

[14] Kohei Arai, Kurtis Thome, Satoshi Tsuchida, Katsutoshi Maekawa, Hideyuki Tonooka, Early Results from Vicarious Calibration of ASTER/VNIR and SWIR at Test Site in Japan, Journal of Remote Sensing Society of Japan, Vol.21, No.5, pp.448-456, 2001.
[15] Hideyuki Tonooka, F.Palluconi, Tsuneo Matsunaga, Taneomi Katoh, Kohei Arai, Early Results from Vicarious Calibration of ASTER/TIR at Test Site in Japan, Journal of Remote Sensing Society of Japan, Vol.21, No.5, pp.467-474, 2001.

[16] Kohei Arai, Vicarious calibration for solar reflection channels of radiometers onboard satellites with deserted area of data, Advances in Space Research, 39, 1, 13-19, 2007.

[17] Kohei Arai, Vicarious calibration ASTER/VNIR based on the results of aerosol optical property at the test site in Saga, Japan, Journal of Remote Sensing Society of Japan, 28, 3, 246-255, 2008.

[18] Kurtis Thome, Kohei Arai, Satoshi Tsuchida and Stuart Biggar, Vicarious calibration of ASTER via the reflectance based approach, IEEE transaction of GeoScience and Remote Sensing, 46, 10, 32853295, 2008.

[19] Kohei Arai, Error analysis and sensitivity analysis in estimation of aerosol refractive index and size distribution using polarization radiance measurement data for vicarious calibration of remote sensing satellite carrying visible to shortwave infrared radiometer, Journal of Japan Society of Photogrammetry and Remote Sensing, 49, 6, 368-380, 2010.

[20] Kohei Arai, Kenta Azuma, Influence due to aerosol size distribution on vicarious calibration accuracy and influence of calibration accuracy of the used sky radiometer in estimation of aerosol refractive index and size distribution, Journal of Japan Society of Photogrammetry and Remote Sensing, 50, 4, 252-263, 2011.

[21] Kohei Arai, Vicarious calibration based cross calibration of solar reflective channels of radiometers onboard remote sensing satellite and evaluation of cross calibration accuracy through band-to-band data comparisons, International Journal of Advanced Computer Science and Applications, 4, 3, 7-14, 2013.

[22] Kohei Arai, Comparison among cross, onboard, and vicarious calibration for Terra/ASTER/VNIR, International Journal of Advanced Research in Artificial Intelligence, 2, 10, 14-18, 2013.

[23] Kohei Arai, Sensitivity analysis and error analysis of reflectance based vicarious calibration with estimated aerosol refractive index and size distribution derived from measured solar direct and diffuse irradiance as well as measured surface reflectance, International Journal of Advanced Research in Artificial Intelligence, 2, 12, 35-41, 2013.

[24] Kohei Arai, Vicarious calibration data screening method based on variance of surface reflectance and atmospheric optical depth together with cross calibration, International Journal of Advanced Research on Artificial Intelligence, 4, 11, 1-8, 2015.

\section{AUTHOR's PROFILE}

Kohei Arai, He received BS, MS and PhD degrees in 1972, 1974 and 1982, respectively. He was with The Institute for Industrial Science and Technology of the University of Tokyo from April 1974 to December 1978 also was with National Space Development Agency of Japan from January, 1979 to March, 1990. During from 1985 to 1987, he was with Canada Centre for Remote Sensing as a Post Doctoral Fellow of National Science and Engineering Research Council of Canada. He moved to Saga University as a Professor in Department of Information Science on April 1990. He was a councilor for the Aeronautics and Space related to the Technology Committee of the Ministry of Science and Technology during from 1998 to 2000 . He was a councilor of Saga University for 2002 and 2003. He also was an executive councilor for the Remote Sensing Society of Japan for 2003 to 2005. He is an Adjunct Professor of University of Arizona, USA since 1998. He also is Vice Chairman of the Science Commission "A" of ICSU/COSPAR since 2008 then he is now award committee member of ICSU/COSPAR. He wrote 37 books and published 570 journal papers. He received 30 of awards including ICSU/COSPAR Vikram Sarabhai Medal in 2016, and Science award of Ministry of Mister of Education of Japan in 2015. He is now Editor-in-Chief of IJACSA and IJISA. http://teagis.ip.is.saga-u.ac.jp/index.ht 